\title{
Cancer Phototherapy via Selective Photoinactivation of Respiratory Chain Oxidase to Trigger a Fatal Superoxide Anion Burst
}

\author{
Shengnan Wu, ${ }^{1,2}$ Feifan Zhou,,2 Yanchun Wei, Wei R. Chen,, Qun Chen,, and Da Xing,1,2
}

\begin{abstract}
Aims: Here, we develop a novel cancer treatment modality using mitochondria-targeting, high-fluence, lowpower laser irradiation (HF-LPLI) in mouse tumor models and explore the mechanism of mitochondrial injury by HF-LPLI. Results: We demonstrated that the initial reaction after photon absorption was photosensitization of cytochrome c oxidase (COX), to inhibit enzymatic activity of COX in situ and cause respiratory chain superoxide anion $\left(\mathrm{O}_{2}{ }^{-}\right)$burst. We also found that HF-LPLI exerted its main tumor killing effect through mitochondrial $\mathrm{O}_{2}^{-}$burst via electron transport chain (ETC). These phenomena were completely absent in the respiration-deficient cells and COX knockdown cells. With a carefully selected irradiation protocol, HF-LPLI could efficaciously destroy tumors. The inhibition of enzymatic activity of COX and generation of $\mathrm{O}_{2}{ }^{-\bullet}$ by HFLPLI in vivo were also detected. Innovation: It is the first time that the mechanism involved in the interaction between light and its photoacceptor under HF-LPLI treatment is clarified. Our results clearly indicate that HFLPLI initiates its effects via targeted COX photoinactivation and that the tumor-killing efficacy is dependent of the subsequent mitochondrial $\mathrm{O}_{2}^{-\bullet}$ burst via ETC. Conclusion: Based on both in vitro and in vivo results, we conclude that HF-LPLI can selectively photoinactivate respiratory chain oxidase to trigger a fatal mitochondrial $\mathrm{O}_{2}{ }^{-\bullet}$ burst, producing oxidative damage on cancer cells. This study opens up the possibilities of applications of HF-LPLI as a mitochondria-targeting cancer phototherapy. Antioxid. Redox Signal. 20, 733-746.
\end{abstract}

\section{Introduction}

A S A TARGETED TREATMENT MODALITY using focused light, low-power laser irradiation (LPLI) in the red (620$760 \mathrm{~nm}$ ) to near infrared region (NIR, 760-1000 $\mathrm{nm}$ ) has been employed by many health specialists and general practitioners to treat a broad range of conditions, mainly centered on pain alleviation, inflammation inhibition, and wound healing (44). These beneficial effects of LPLI at low fluence are attributed to its cell promotive effect via an increase in cell viability or cell proliferation $(10,39)$. However, Zhang et al. demonstrated that $632.8-\mathrm{nm}$ LPLI from 3 to $15 \mathrm{~J} / \mathrm{cm}^{2}$ increased cell viability, while $50 \mathrm{~J} / \mathrm{cm}^{2}$ LPLI significantly inhibited cell viability in HeLa cells (46). Murayama et al. reported that $808-\mathrm{nm}$ LPLI from 18 to $54 \mathrm{~J} / \mathrm{cm}^{2}$ suppressed the proliferation of A-172 human-derived glioblastoma cells in a

\section{Innovation}

Low-power laser irradiation (LPLI) has been used by many health specialists and general practitioners to treat a broad range of illnesses. Currently, we developed highfluence, low-power laser irradiation (HF-LPLI) as a novel cancer treatment modality using a mitochondria-targeted laser $(635 \mathrm{~nm})$ and explored the mechanism involved in the interaction between the light and its photoacceptor. Our results clearly demonstrated that HF-LPLI initiated its effects via targeted cytochrome c oxidase photoinactivation and that the tumor-killing efficacy was dependent on the subsequent mitochondrial superoxide anion burst via electron transport chain. We conclude that the mitochondriatargeting HF-LPLI is feasible and effective, and may be of significant clinical importance in treating solid cancer.

${ }^{1}$ MOE Key Laboratory of Laser Life Science and Institute of Laser Life Science, College of Biophotonics, South China Normal University, Guangzhou, China.

${ }^{2}$ Joint Laboratory of Laser Oncology with Cancer Center of Sun Yat-sen University, South China Normal University, Guangzhou, China. 
dose-dependent manner (25). Frigo et al. reported that 660-nm LPLI at $21 \mathrm{~J} / \mathrm{cm}^{2}$ negatively affected $3 T 3$ murine fibroblast cells, as it increased cell death and inhibited cell proliferation (9). Our earlier study first reported that $632.8-\mathrm{nm}$ LPLI at $60 \mathrm{~J} / \mathrm{cm}^{2}$, which was named high-fluence, low-power laser irradiation (HF-LPLI), could induce cancer cell apoptosis, as evidenced by caspase- 3 activation (35).

The ideal treatment modality for cancer should achieve tumor destruction via a minimally invasive local intervention. As the gateway of the intrinsic pathway for apoptosis, mitochondrial destruction represents a point of no return in many models of apoptosis (22). As a result, mitochondria have been considered potential targets for cancer therapy (12). Previously, we found that HF-LPLI $\left(633 \mathrm{~nm}, 120 \mathrm{~J} / \mathrm{cm}^{2}\right)$ could induce cancer cell apoptosis in vitro via an intrinsic mitochondrial pathway by triggering the generation of reactive oxygen species (ROS) $(40,41)$. We demonstrated the mitochondrial pathway by HF-LPLI, as evidenced by the inactivation of caspase-8 (41), the activation of caspase-9 (5), and the release of cytochrome c (40). We also found that HF-LPLI induced the mitochondrial pathway via the induction of ROSmediated mitochondrial permeability transition (MPT) (40). Another pro-apoptotic signaling pathway comprising the inactivation of protein kinase B/glycogen synthase kinase 3 beta on HF-LPLI was also explored (16). Although the initial mechanism involved in HF-LPLI-induced ROS generation is still unknown, these reports suggest that LPLI at higher doses can be used for cancer therapy via laser focusing and mitochondrial targeting.

The photobiological reactions of LPLI involve the absorption of photons at a specific wavelength by functioning photoacceptor molecules $(19,33)$. Cytochrome c oxidase (COX) is the terminal enzyme (complex IV) of the electron transport chain (ETC) in eukaryotic cells and mediates the transfer of electrons from cytochrome $c$ to molecular oxygen $\left(\mathrm{O}_{2}\right)(34)$. COX has been increasingly shown to be the photoacceptor and photosignal transducer in the red-to-NIR region of light $(7,19,28)$. It has long been known that electronic excitation by light stimulates redox processes in organic dyes to intensify electron transfer (24). Similarly, it is quite possible that LPLI makes more electrons available for the reduction of $\mathrm{O}_{2}$ in the catalytic center of COX (heme a3-CuB site). The increase in the availability of electrons can be the crucial result of LPLI in situations in which all the four electrons are unavailable for the reduction of $\mathrm{O}_{2}$. The COX absorption of LPLI at low fluence has been reported to increase its enzymatic activity, increase the mitochondrial transmembrane potential $(\Delta \Psi \mathrm{m})$, and increase the levels of ATP, cyclic adenosine monophosphate, and ROS, leading to increased energy availability and signal transduction $(7,10,19,39)$. However, the initial interaction between light and COX under HF-LPLI is still unknown.

Inducing local cellular damage via the modulation of ROS production is likely to cause less systematic side effect compared with other modalities, and its potential in the treatment of various health conditions has already been demonstrated clinically. Here, we develop a novel cancer treatment modality using HF-LPLI and investigate the initial mechanism of ROS generation by HF-LPLI. We found that HF-LPLI at the range of red light $(635 \mathrm{~nm})$ could selectively photoinactivate its endogenous photoacceptor COX to generate a mitochondrial superoxide anion $\left(\mathrm{O}_{2}^{-\bullet}\right)$ burst, resulting in oxidative damage to cancer cells. This mitochondria-targeting phototherapy reaches sufficient antitumor efficacy without the administration of exogenous chemicals.

\section{Results}

\section{In vitro tumor killing efficacy of HF-LPLI via ROS generation}

Our previous study showed that either HF-LPLI or photodynamic therapy (PDT) could induce cell apoptosis via the mitochondrial pathway by triggering the generation of ROS $(41,42)$. To confirm the damage effect of ROS generated by HF-LPLI, we studied the correlation between ROS generation and mitochondrial injury in human lung adenocarcinoma cell line (ASTC-a-1) cells (Fig. 1). The cells were stained with $2^{\prime}, 7^{\prime}$-dichlorodihydrofluorescein diacetate, succinimidyl ester $\left(\mathrm{H}_{2}\right.$ DCFDA, $\left.\mathrm{SE}\right)$, and tetramethylrhodamine methyl ester (TMRM) dyes and imaged using confocal microscopy under various conditions. The representative sequential images show that the decrease in TMRM intensity corresponds closely to the increase in $2^{\prime}, 7^{\prime}$-dichlorofluorescein (DCF) intensity after both PDT and HF-LPLI treatment, indicating that HF-LPLI induces a decrease in $\triangle \Psi \mathrm{m}$ along with ROS generation, similar to the results with PDT (Fig. 1A). Using flow cytometry (FACS) analysis, we then detected ROS generation (Fig. 1B) and $\Delta \Psi \mathrm{m}$ collapse (Fig. 1C) in ASTC-a-1 cells, and cell apoptosis in human lung adenocarcinoma cell line (A549; Fig. 1D), ASTC-a-1 (Supplementary Figs. S1 and S2; Supplementary Data are available online at www.liebertpub.com/ars), and mouse mammary tumor cell line (EMT6 cells) (Supplementary Fig. S2) after HF-LPLI treatment. These phenomena were completely prevented in the presence of the broad-spectrum antioxidant $\mathrm{N}$-acetyl-L-cysteine (NAC) or dehydroascorbic acid (DHA) (Fig. 1B-D and Supplementary Figs. S1 and S2), supporting the hypothesis that ROS generation is crucial for mitochondrial injury and cell apoptosis by HF-LPLI. These results demonstrated that HF-LPLI could efficiently induce mitochondrial depolarization and a high level of tumor cell apoptosis by triggering ROS generation. To evaluate the intracellular oxidative damage by HF-LPLI, we examined the extent of lipid, protein, and DNA oxidation in three different cell lines ASTC-a-1, A549, and EMT6 (Fig. 1E-G). Malondialdehyde, protein carbonyls, and 8hydroxydeoxyguanosine were significantly increased in these cells $6 \mathrm{~h}$ after HF-LPLI. NAC pre-treatment prevented the effect of HF-LPLI-induced oxidative damage on lipid, protein, and DNA (Fig. 1E-G).

\section{Mitochondrial $\mathrm{O}_{2}^{-\bullet}$ burst by HF-LPLI}

To explore the initial site of ROS generation, A549 cells stained with $\mathrm{H}_{2}$ DCFDA, SE dye, and expressing DsRed-mit (labels mitochondria) were imaged using confocal microscopy immediately after HF-LPLI or PDT treatment. As shown in Figure 2A, the co-localization of the DCF and DsRed-mit emissions clearly shows that the initial site of ROS generation by HF-LPLI is primarily in mitochondria, similar to the results with PDT. Studies performed in ASTC-a-1 and A549 cells with dihydroethidium (DHE) and MitoTraker Deeper Red 633 (MTR, labels mitochondria) dyes revealed that the initial site of $\mathrm{O}_{2}{ }^{-\bullet}$ generation by HF-LPLI was primarily in mitochondria 

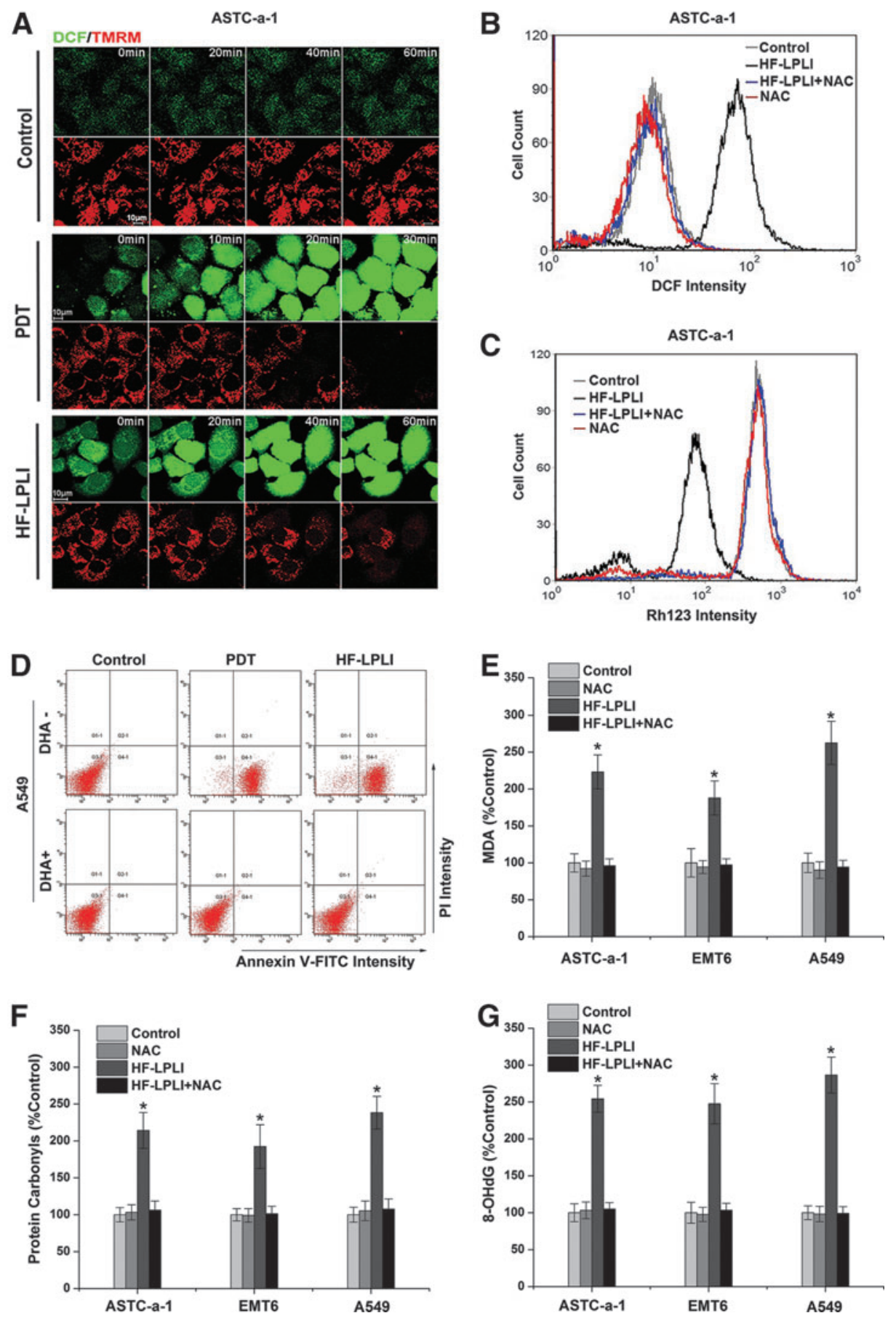

FIG. 1. In vitro tumor-killing efficacy of HF-LPLI $\left(200 \mathrm{~mW} / \mathrm{cm}^{2}\right.$ at $\left.10 \mathrm{~min}\right)$ through ROS generation. (A) ROS generation and mitochondrial depolarization. Representative sequential images of ASTC-a-1 cells double stained with $\mathrm{H}_{2}$ DCFDA, SE, and TMRM were acquired after PDT or HF-LPLI treatment. (B, C) FACS analysis of ROS generation and $\triangle \Psi m$ changes. The temporal profiles of the DCF (B) and Rh123 (C) intensities in ASTC-a-1 cells were acquired $1 \mathrm{~h}$ after HF-LPLI treatment. Cells were pre-cultured with NAC $(250 \mu \mathrm{M}) 1 \mathrm{~h}$ before HF-LPLI. (D) Cell death analysis was performed by annexin VFITC/PI double staining in A549 cells $3 \mathrm{~h}$ and $10 \mathrm{~h}$ after PDT and HF-LPLI treatment, respectively. Cells were pre-cultured with DHA $(250 \mu M) 1 \mathrm{~h}$ before HF-LPLI. (E-G) Detection of the effect of oxidative damage on lipid, protein, and DNA. Levels of MDA (E), protein carbonyls (F), and 8-OHdG (G) in three different cell lines ASTC-a-1, A549, and EMT6 were detected $6 \mathrm{~h}$ after HF-LPLI treatment. Cells were pre-cultured with NAC $(250 \mu M) 1 \mathrm{~h}$ before HF-LPLI. The data represent the mean $\pm \mathrm{SD}(n=5)$. ${ }^{*} P<0.05$ versus control. 8-OHdG, 8-hydroxydeoxyguanosine; A549, human lung adenocarcinoma cell line; ASTC-a-1, human lung adenocarcinoma cell line; DCF, 2' $7^{\prime}$-dichlorofluorescein; DHA, dehydroascorbic acid; EMT6, mouse mammary tumor cell line; FACS, flow cytometry; FITC, fluorescein isothiocyanate; $\mathrm{H}_{2}$ DCFDA, SE, 2',7'-dichlorodihydrofluorescein diacetate, succinimidyl ester; HF-LPLI, high fluence low-power laser irradiation; MDA, malondialdehyde; NAC, N-acetyl-L-cysteine; PDT, photodynamic therapy; PI, propidium iodide; Rh123, rhodamine 123; ROS, reactive oxygen species; SD, standard deviation; TMRM, tetramethylrhodamine methyl ester; $\Delta \Psi \mathrm{m}$, mitochondrial transmembrane potential. To see this illustration in color, the reader is referred to the web version of this article at www .liebertpub.com/ars 
A
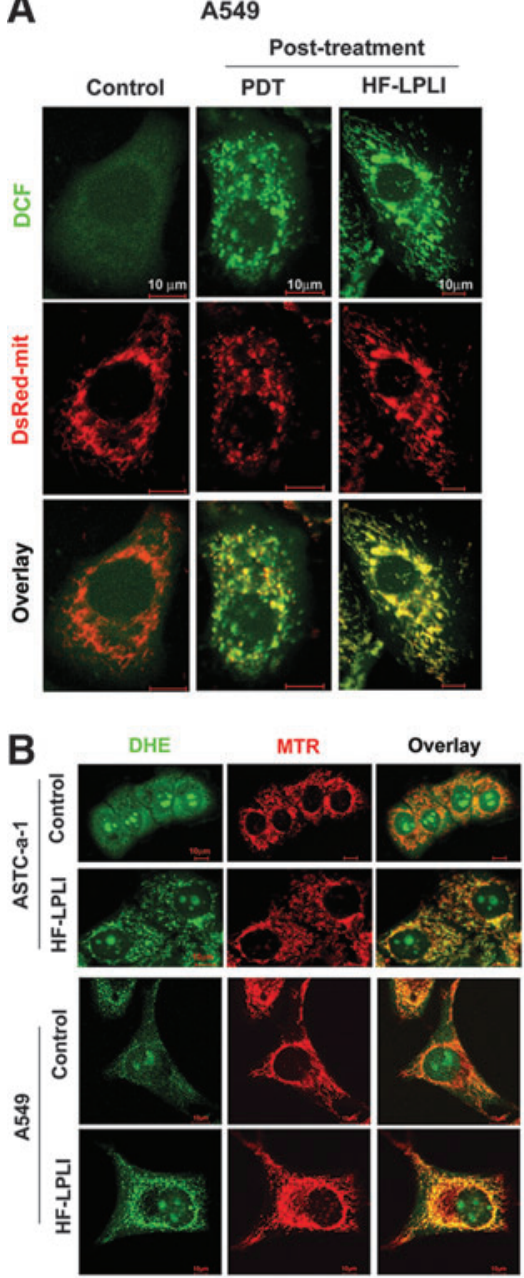

F

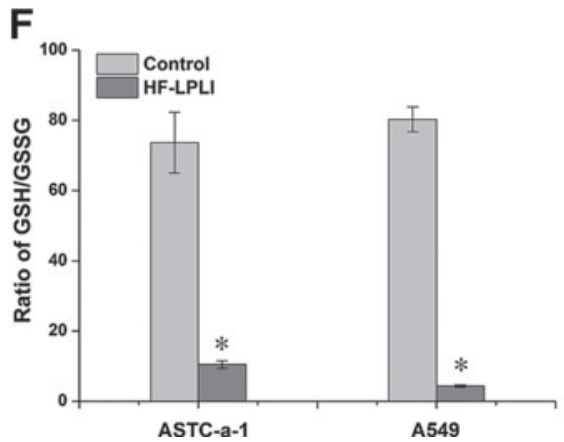

C

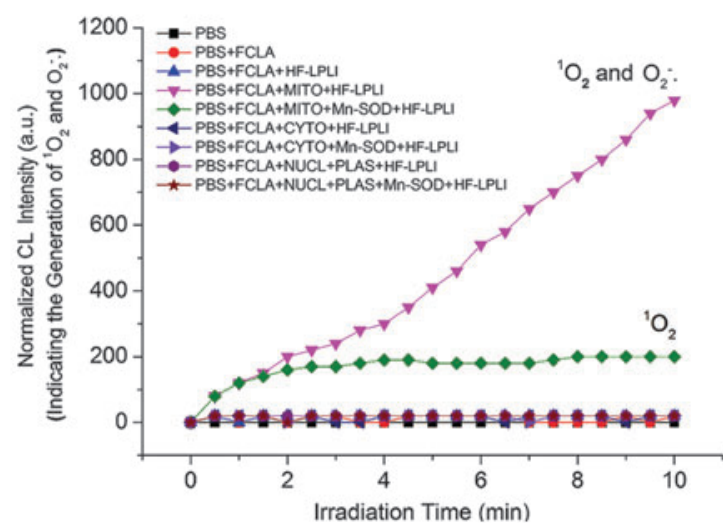

D

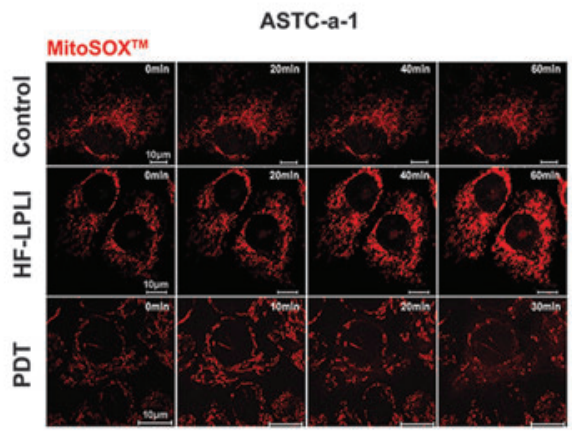

E

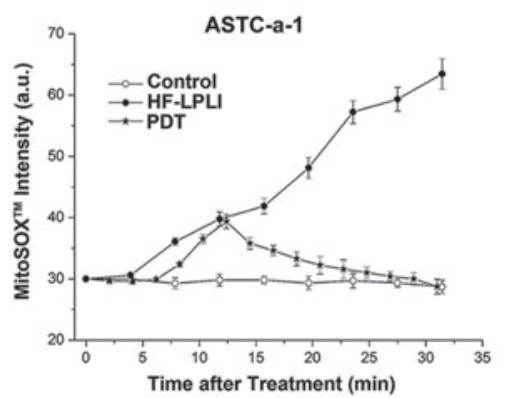

G

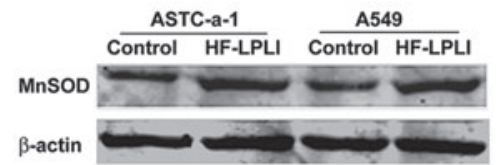

FIG. 2. Detection of mitochondrial $\mathrm{O}_{2}{ }^{-\bullet}$ generation stimulated by HF-LPLI $\left(200 \mathrm{~mW} / \mathrm{cm}^{2}\right.$ at $\left.10 \mathrm{~min}\right)$. (A) Monitoring of initial ROS generation stimulated by HF-LPLI. The fluorescence images of A549 cells overlaid with $\mathrm{H}_{2} \mathrm{DCFDA}$, SE dye, and DsRed-mit fluorescence protein were acquired immediately after PDT or HF-LPLI treatment. (B) Monitoring of initial $\mathrm{O}_{2}{ }^{-\bullet}$ generation stimulated by HF-LPLI. The fluorescence images of ASTC-a-1 and A549 cells overlaid with DHE and MTR dyes were acquired immediately after HF-LPLI treatment. (C) Subcellular fractions (MITO, mitochondria; CYTO, cytosol; NUCL, nucleus; PLAS, plasma membrane) of primary mouse liver cells pre-incubated with FCLA were subjected to HF-LPLI. Data were collected during irradiation. Subcellular fractions were pre-cultured with SOD (50 U/ml) $1 \mathrm{~h}$ before HF-LPLI. (D) The dynamics of mitochondrial $\mathrm{O}_{2}{ }^{-}$generation. The sequential images of ASTC-a-1 cells stained with MitoSOX ${ }^{\mathrm{TM}}$ dye were acquired after PDT or HF-LPLI treatment. (E) The quantitative analysis of the mitochondrial $\mathrm{O}_{2}^{-}{ }^{-}$generation is shown in (D). The data represent the mean \pm SD $(n=5)$. (F) Ratio of GSH and GSSG in ASTC-a- 1 and A549 cells $2 \mathrm{~h}$ after HF-LPLI treatment. The data represent the mean $\pm S D(n=5) .{ }^{*} P<0.05$ versus control. (G) Western blot analysis of MnSOD levels in protein extracts from ASTC-a-1 and A549 cells $2 \mathrm{~h}$ after HF-LPLI. $\beta$-Actin was blotted as a control for protein loading. DHE, dihydroethidium; FCLA, fluoresceinyl cypridina luciferin analog; GSH, glutathione; GSSG, oxidized glutathione; MnSOD, manganese superoxide dismutase; MTR, MitoTraker Deeper Red 633; $\mathrm{O}_{2}{ }^{-\bullet}$, superoxide anion; SOD, superoxidase dismutase. To see this illustration in color, the reader is referred to the web version of this article at www. liebertpub.com/ars 
FIG. 3. In vitro tumor-killing efficacy of HF-LPLI $\left(200 \mathrm{~mW} / \mathrm{cm}^{2}\right.$ at $\left.10 \mathrm{~min}\right)$ in respiration-deficient cells. (A, B) FACS analysis of mitochondrial $\mathrm{O}_{2}{ }^{-\bullet}$ generation in $\rho^{0}$ ASTC-a-1 (A) and $\rho^{0} \mathrm{~A} 549$ (B) cells. The temporal profiles of MitoSOX ${ }^{\mathrm{TM}}$ intensities were acquired in cells $1 \mathrm{~h}$ after HF-LPLI treatment. (C) ASTC-a-1 and $\rho^{0}$ ASTC-a-1 cells pre-incubated with FCLA received various treatments. Cells were pre-cultured with SOD $(50 \mathrm{U} / \mathrm{ml}) 1 \mathrm{~h}$ before HFLPLI. Data represent the mean \pm SD $\quad(n=5) . \quad{ }^{*} P<0.05$ versus control; $* * P<0.01$ versus control. (D) FACS analysis of cell apoptosis with annexin V-FITC staining in ASTC-a- 1 and $\rho^{0}$ ASTC-a-1 cells $10 \mathrm{~h}$ after HF-LPLI treatment. (E) The quantitative analysis of the cell apoptosis ratio shown in (D) and Supplementary Figure S6. The data represent the mean \pm SD $\quad(n=5) . \quad{ }^{* *} P<0.01$ versus control.
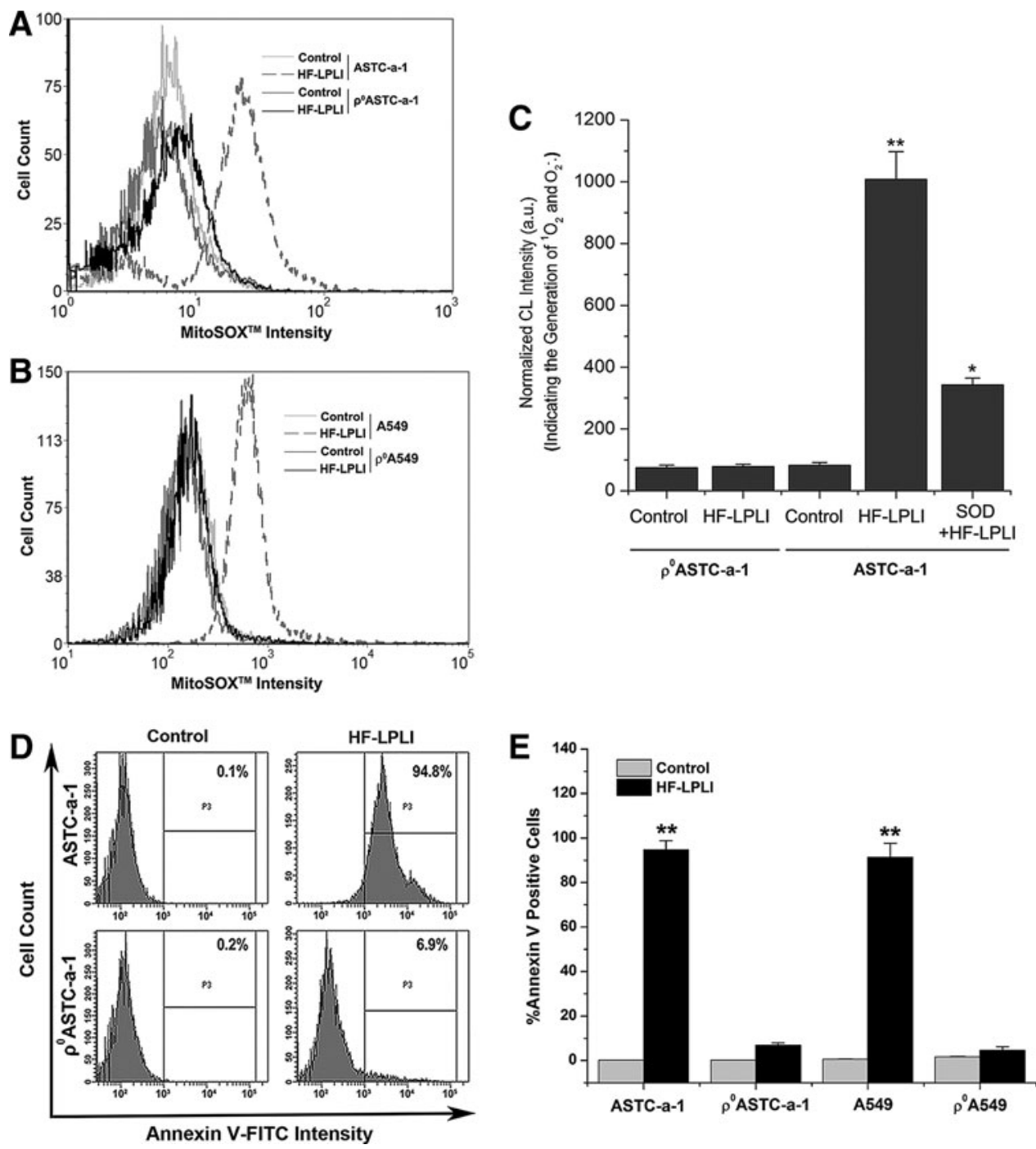

(Fig. 2B). We used fluoresceinyl cypridina luciferin analog (FCLA)-based chemiluminescence (CL) to detect $\mathrm{O}_{2}{ }^{-\bullet}$ and singlet oxygen $\left({ }^{1} \mathrm{O}_{2}\right)$ generation during treatment of HF-LPLI (Fig. 2C). The subcellular fractions of primary mouse liver cells incubated with FCLA were subjected to HF-LPLI with or without superoxidase dismutase (SOD) exposure. Positive CL signals, representing the generation of $\mathrm{O}_{2}{ }^{-\bullet}$ and ${ }^{1} \mathrm{O}_{2}$, were only detected in the mitochondrial fraction. SOD exposure significantly reduced the HF-LPLI-triggered CL signal in the mitochondrial fraction.

To confirm the generation of mitochondrial $\mathrm{O}_{2}{ }^{-\bullet}$ after HFLPLI, A549 cells stained with MitoSOX ${ }^{\mathrm{TM}}$ dye were subjected to FACS analysis (Supplementary Fig. S3). The MitoSOX ${ }^{\mathrm{TM}}$ intensity obviously increased after HF-LPLI, compared with the low increase observed in the control cells. SOD exposure largely inhibited HF-LPLI-induced mitochondrial $\mathrm{O}_{2}{ }^{-}$generation. We monitored the dynamic generation of mitochondrial $\mathrm{O}_{2}^{-}$after HF-LPLI or PDT treatment in ASTC-a-1 cells stained with MitoSOX ${ }^{\mathrm{TM}}$ dye using confocal microscopy (Fig. 2D, E). The MitoSOX ${ }^{\mathrm{TM}}$ intensity increased quickly after HFLPLI treatment, indicating a mitochondrial $\mathrm{O}_{2}{ }^{-\bullet}$ burst. After PDT treatment, the MitoSOX ${ }^{\mathrm{TM}}$ intensity increased in the first $10 \mathrm{~min}$ and then decreased gradually, indicating the rupture of the mitochondrial membrane (48). These results suggest that HF-LPLI induces a selectively mitochondrial $\mathrm{O}_{2}{ }^{-\bullet}$ burst with mitochondrial membrane integrity, while PDT ruptures the mitochondrial membrane after the initial oxidized reaction of the photosensitizer.

The expression of manganese superoxide dismutase (MnSOD) was induced by HF-LPLI in both ASTC-a-1 and A549 cells (Fig. 2G), suggesting a protective mechanism initiated by these cells against oxidative stress. Oxidative stress always causes an intracellular increase in oxidized glutathione (GSSG) levels concurrent with a decrease in glutathione (GSH) levels. Cellular GSSG/GSH ratio in both ASTC-a-1 and A549 cells increased $2 \mathrm{~h}$ after HF-LPLI treatment (Fig. 2F).

\section{In vitro tumor cell-killing efficacy of HF-LPLI depends} on the mitochondrial $\mathrm{O}_{2}^{-\bullet}$ burst

We generated two respiration-deficient cell lines $\rho^{0}$ ASTCa- 1 and $\rho^{0}$ A549 (Supplementary Figs. S4 and S5) to inhibit the mitochondrial $\mathrm{O}_{2}{ }^{-\bullet}$ generation via ETC. To analyze the mitochondrial $\mathrm{O}_{2}{ }^{-}$generation between wild-type cells and $\rho^{0}$ cells, we used FACS analysis with MitoSOX ${ }^{\mathrm{TM}}$ dye (Fig. 3A, B) and CL detection with FCLA probe (Fig. 3C). After HF-LPLI, no positive MitoSOX ${ }^{\mathrm{TM}}$ signal was detected in the $\rho^{0}$ cells compared with a strong signal detected in wild-type cells (Fig. 

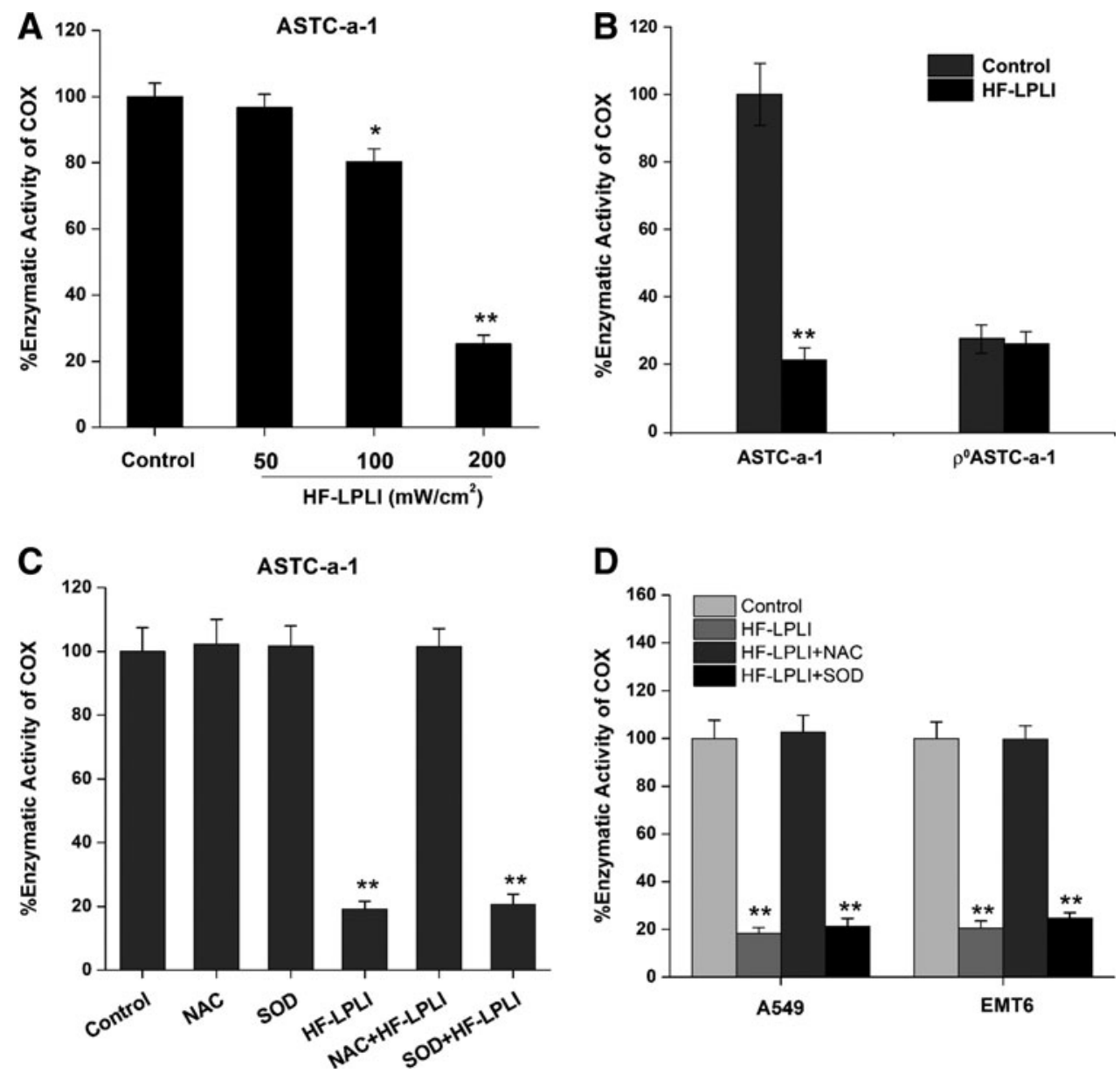

FIG. 4. Assay of the enzymatic activity of COX after HF-LPLI treatment $(200 \mathrm{~mW} /$ $\mathrm{cm}^{2}$ at $10 \mathrm{~min}$ ). (A) Enzymatic activity of COX was assayed by measuring cytochrome c oxidation in ASTCa-1 cells after HF-LPLI treatment with different laser doses. (B) Enzymatic activity of COX was assayed in ASTC-a1 and $\rho^{0}$ ASTC-a- 1 cells treated by HF-LPLI. (C) Effect of ROS scavengers on the enzymatic activity of COX in ASTC-a-1 cells treated by HF-LPLI. Cells were pre-cultured with NAC $(250 \mu \mathrm{M})$ or SOD $(50 \mathrm{U} / \mathrm{ml}) \quad 1 \mathrm{~h}$ before HF-LPLI. (D) Enzymatic activity of COX was assayed in A549 and EMT6 cells after HF-LPLI treatment with or without ROS scavengers. Cells were pre-cultured with NAC $(250 \mu M)$ or SOD (50 U/ $\mathrm{ml}) 1 \mathrm{~h}$ before HF-LPLI. All the data in this figure represent the mean $\pm S D \quad(n=5)$. ${ }^{*} P<0.05$ versus control; $* * P<0.01$ versus control. COX, cytochrome c oxidase.
3A, B), indicating that HF-LPLI fails to induce mitochondrial $\mathrm{O}_{2}{ }^{-\bullet}$ burst in ETC-deficient cells. Similar results were obtained using CL detection (Fig. 3C).

To determine the effect of mitochondrial $\mathrm{O}_{2}{ }^{-\bullet}$ burst on cell apoptosis after HF-LPLI, wild-type cells and $\rho^{0}$ cells were analyzed using FACS with annexin V-fluorescein isothiocyanate (FITC) staining. Ten hours after HF-LPLI, the wild-type cells showed a high level of apoptosis, while the $\rho^{0}$ ASTC-a- 1 and $\rho^{0}$ A549 cells had only a low level of apoptosis, as shown in Figure 3D and E, and Supplementary Figure S6. These results indicate that the mitochondrial $\mathrm{O}_{2}{ }^{-\bullet}$ burst via ETC is highly likely the determinant of HF-LPLIinduced cell apoptosis.

\section{Photoinactivation of COX induced by HF-LPLI causes mitochondrial $\mathrm{O}_{2}^{-\bullet}$ burst}

COX is believed to be the photoacceptor of LPLI in the redto-NIR region $(7,19,28)$. The effect of HF-LPLI on COX was investigated by evaluating the enzymatic activity of COX. The COX activity in ASTC-a-1 cells treated with $120 \mathrm{~J} / \mathrm{cm}^{2}$ HF-LPLI was decreased to 0.25 -fold of the control cells, demonstrating that HF-LPLI significantly inhibits the enzymatic activity (Fig. 4A). However, no enzymatic activity of COX could be detected in the $\rho^{0}$ ASTC-a- 1 cells, and there was no change under HF-LPLI treatment (Fig. 4B).

SOD exposure had almost no effect on the inactivation of COX in ASTC-a-1 cells after HF-LPLI (Fig. 4C), indicating that the mitochondrial $\mathrm{O}_{2}{ }^{-\bullet}$ burst most likely results from COX photoinactivation. In contrast, NAC exposure completely reversed the inactivation of COX by HF-LPLI (Fig. 4C), indicating that in situ oxidative damage is most likely the cause of COX photoinactivation. Similar results were obtained in A549 and EMT6 cell lines (Fig. 4D). These results suggest that HF-LPLI causes COX inactivation via the initial photosensitized products and then triggers a mitochondrial $\mathrm{O}_{2}{ }^{-\bullet}$ burst via ETC.

We used a gene silencing approach to explore whether the changes in the enzyme activity of COX contributed to the mitochondrial $\mathrm{O}_{2}^{-}$burst and the oxidative damage of cells after HF-LPLI. The more efficient small interfering RNAs specifically targeting the subunits of COX were selected to suppress COX activity in ASTC-a-1 (Fig. 5A) and A549 (Supplementary Fig. S7) cells. The ROS levels in COXdeficient cells were assayed using $\mathrm{H}_{2}$ DCFDA, SE dye. No obvious changes in the ROS level were detected in the COX II or COX III knockdown cells (Data not shown). As shown in Figure 5B, HF-LPLI-induced mitochondrial $\mathrm{O}_{2}^{-\bullet}$ generation depends on the activity of COX, because the MitoSOX ${ }^{\mathrm{TM}}$ intensity in COX III knockdown cells treated with HF-LPLI was nearly the same as that in control cells. The analysis of cell apoptosis based on annexin V-FITC/propidium iodide (PI) double staining showed that when the activity of COX was completely inhibited, the cell apoptosis by HF-LPLI was completely prevented (Fig. 5C, D and Supplementary Fig. S8). The results showed that photoinactivation of COX caused mitochondrial $\mathrm{O}_{2}^{-\bullet}$. burst and cell apoptosis. 
FIG. 5. In vitro tumorkilling efficacy of HF-LPLI $\left(200 \mathrm{~mW} / \mathrm{cm}^{2}\right.$ at $\left.10 \mathrm{~min}\right)$ in COX knockdown cells. (A) Effect of HF-LPLI on COX activity in COX subunit knockdown ASTC-a-1 cells generated with two different siRNAs specifically targeting COX II and COX III. The data represent the mean \pm $\mathrm{SD}(n=5)$. (B) FACS analysis of mitochondrial $\mathrm{O}_{2}{ }^{-\bullet}$ generation. The temporal profiles of MitoSOX ${ }^{\mathrm{TM}}$ intensity were acquired in COX subunit knockdown ASTC-a-1 cells $1 \mathrm{~h}$ after HF-LPLI treatment. (C) FACS analysis of cell death with annexin $\mathrm{V}$ FITC/PI double staining in COX subunit knockdown ASTC-a- 1 cells $10 \mathrm{~h}$ after HFLPLI treatment. (D) Quantitative analysis of the cell death rate shown in $(\mathbf{C})$ and Supplementary Figure S8. The data represent the mean $\pm \mathrm{SD} \quad(n=5)$. siRNA, small interfering RNA.
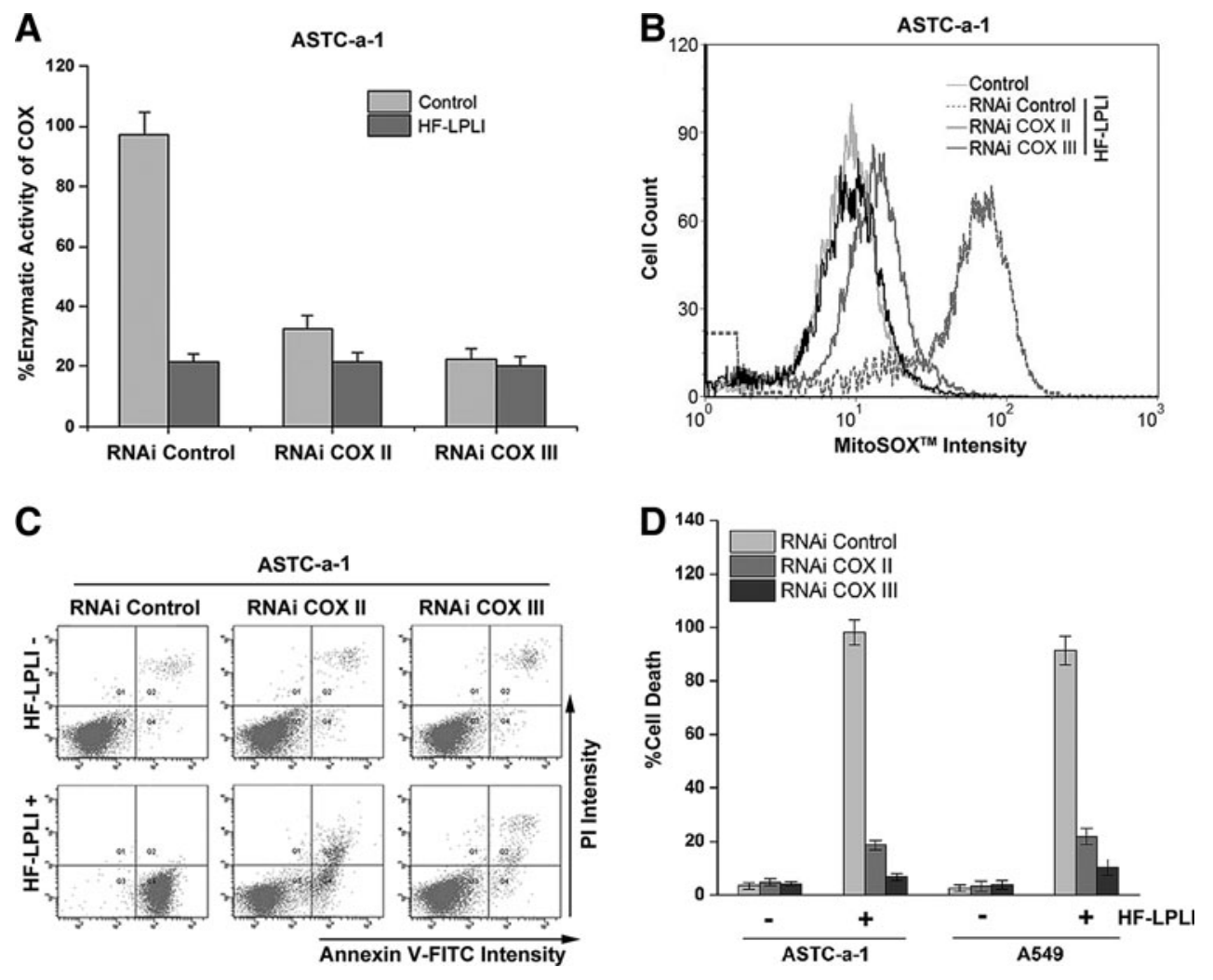

In vivo tumor-killing efficacy of HF-LPLI

The tumor-killing efficacy of HF-LPLI was evaluated with ASTC-a-1 xenografted tumor model. First, the power intensity and irradiation time of HF-LPLI at the fluence of $1200 \mathrm{~J} / \mathrm{cm}^{2}$ was screened by evaluating the mean tumor volume. The tumor size was recorded for 36 days, and the results showed that HF-LPLI at the fluence of $500 \mathrm{~mW} / \mathrm{cm}^{2}$ for $40 \mathrm{~min}$ was the most efficacious in tumor reduction, resulting in tumors which were significantly smaller than those of the control groups (Fig. 6A). For the survival studies, mice were monitored for 100 days after tumor inoculation. Kaplan-Meier survival curves showed that $95 \%$ of the HF-LPLI-treated mice and $100 \%$ of the Photofrin-PDT-treated mice were still alive on day 60 , whereas no control mice survived beyond day 40 (Fig. 6B). A further study was performed to investigate the tumor-killing efficacy with hematoxylin and eosin (H\&E) staining and annexin V-FITC staining 1 day after HF-LPLI treatment. A high scathe level was observed in the cells treated with HF-LPLI (Fig. 6C). These results demonstrated that HF-LPLI was an efficacious modality for cancer treatment.

We investigated the tumor-killing efficacy of HF-LPLI with a $\rho^{0}$ ASTC-a-1 xenografted tumor model. Compared with the control group, there was no reduction of tumor size in the HF-LPLI-treated group (Fig. 6D). Next, we monitored ROS generation in vivo using FCLA-based CL during HF-LPLI treatment (Fig. 6E). The injection of SOD was used to scavenge the $\mathrm{O}_{2}{ }^{-}$generated. The results clearly demonstrate that HF-LPLI caused in vivo $\mathrm{O}_{2}{ }^{-\bullet}$ generation, as evidenced by the strong CL signal detected during HF-LPLI treatment in ASTC-a-1 tumor model. However, there was no $\mathrm{O}_{2}{ }^{-\bullet}$ generation detection in $\rho^{0}$ ASTC-a- 1 tumor model treated by HF-LPLI. We detected the enzymatic activity of COX $1 \mathrm{~h}$ post HF-LPLI treatment in the ASTC-a-1 tumor model, and performed terminal deoxynucleotidyl transferase dUTP nick end labeling (TUNEL) assay 1 day after HF-LPLI treatment. Compared with the control group, the 3,3'-diaminobenzidine (DAB) level was significantly decreased in the HF-LPLI-treated group, demonstrating that HF-LPLI significantly inhibits the enzymatic activity of COX in this tumor model, according to highlevel cell death by HF-LPLI (Fig. 6F). These results suggest that the in vivo tumor-killing mechanism of HF-LPLI is an oxidative damage effect with COX photoinactivation.

The EMT6 tumor model was also used to analyze the tumor-killing efficacy of HF-LPLI at $500 \mathrm{~mW} / \mathrm{cm}^{2}$ for $40 \mathrm{~min}$. In the HF-LPLI-treated group, the tumor burden was significantly smaller than that of the control groups (Fig. 7A). The survival rates were $90 \%$ up to day 100 after tumor inoculation (Fig. 7B). A high scathe level was observed in the tumor treated with HF-LPLI as assessed by either TUNEL assay or H\&E staining, corresponded to the decreased enzymatic activity of COX (Fig. 7C). In addition, a thermal imaging camera was used to evaluate the effect of temperature changes on the surface of ASTC-a-1 tumor model during HF-LPLI treatment at the fluence of $500 \mathrm{~mW} / \mathrm{cm}^{2}$ for $40 \mathrm{~min}$. The results show that the temperature reached to $37.8^{\circ} \mathrm{C}$ after HF-LPLI (Fig. 7D). This indicates that thermal effect is an insignificant contributor to the antitumor effect of HF-LPLI.

\section{Discussion}

Here, we report a novel modality for cancer phototherapy using HF-LPLI in an experimental model, explored the 
A

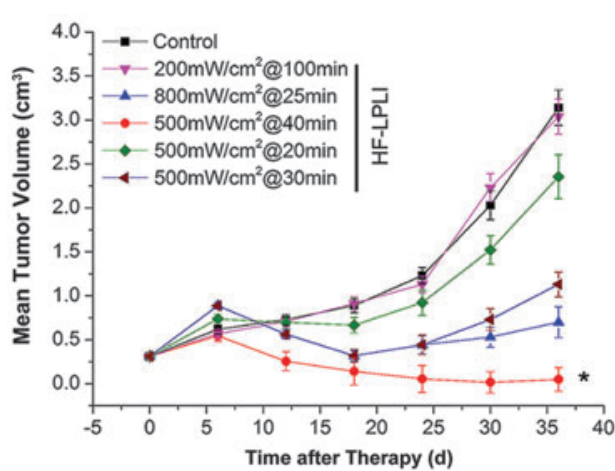

c
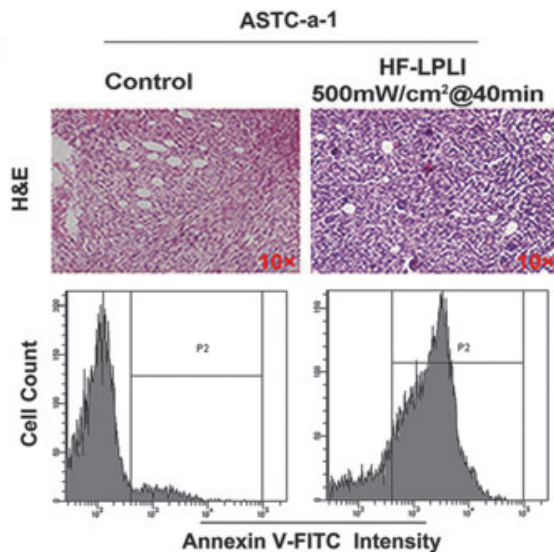

E

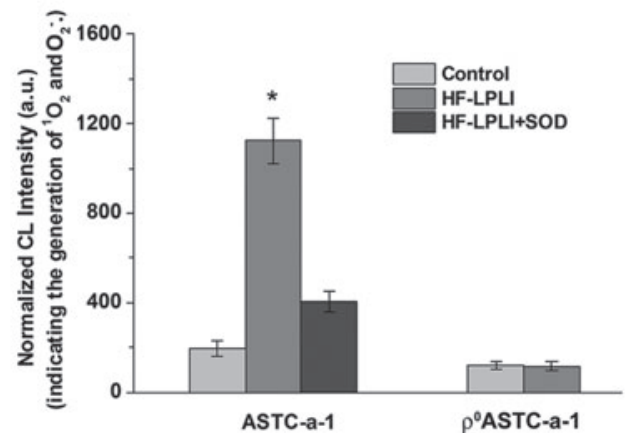

B
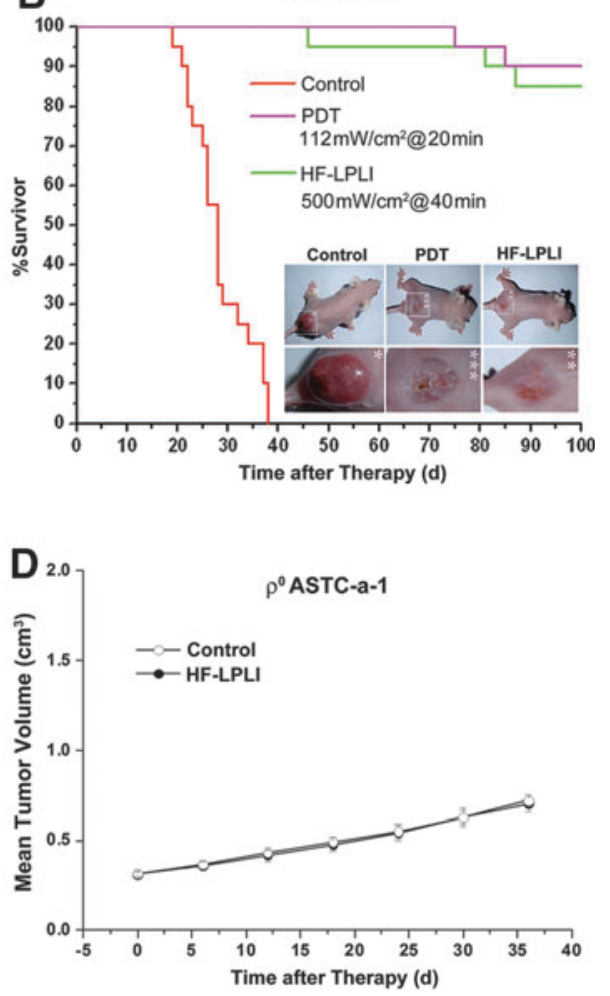

F

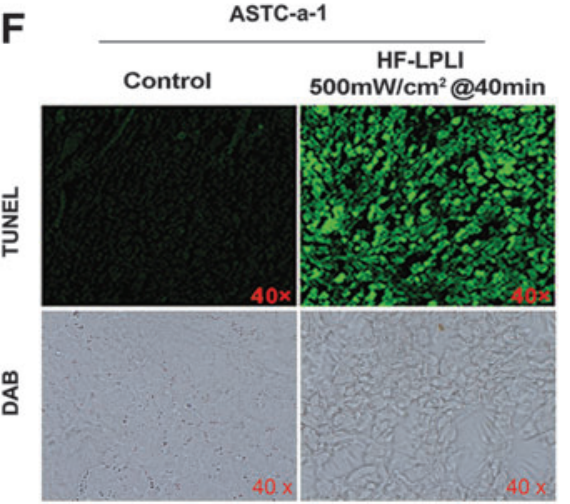

FIG. 6. In vivo tumor-killing efficacy of HF-LPLI in ASTC-a-1-transplanted tumor model. (A, B) Effects of HF-LPLI on ASTC-a-1-transplanted tumors in nude mice. (A) Volumetric change in tumor sizes induced by HF-LPLI at different laser doses. The data represent the mean $\pm \mathrm{SD}(n=10)$. ${ }^{*} P<0.05$ versus control. (B) Kaplan-Meier survival curves show the survival rates of the tumor-bearing mice that received HF-LPLI or PDT $(n=20)$. Representative images of the mice that received HFLPLI or PDT were also shown (inset). (C) Representative images of H\&E-stained specimens at $\times 10$ magnification, and annexin V-FITC staining analysis of tumor 1 day after HF-LPLI treatment. (D) Volumetric change in tumor sizes induced by HF-LPLI in $\rho^{0}$ ASTC-a-1 tumor. The data represent the mean \pm SD $(n=10)$. (E) In vivo monitoring of $\mathrm{O}_{2}^{-\bullet}$ generation in ASTC-a-1 and $\rho^{0}$ ASTC-a-1 tumors using FCLA-based CL after HF-LPLI treatment. FCLA was injected subcutaneously into the HF-LPLI-CL measurement site of the tumor $1 \mathrm{~h}$ before light irradiation to allow for adequate absorption. SOD was used to scavenge the $\mathrm{O}_{2}{ }^{-\bullet}$ generated by HF-LPLI. The data represent the mean \pm SD $(n=5)$. ${ }^{*} P<0.05$ versus control. (F) Representative images of TUNEL- and DAB-stained specimens harvested $1 \mathrm{~h}$ after HF-LPLI treatment. CL, chemiluminescence; DAB, 3,3'-diaminobenzidine; H\&E, hematoxylin and eosin; TUNEL, terminal deoxynucleotidyl transferase dUTP nick end labeling. To see this illustration in color, the reader is referred to the web version of this article at www.liebertpub.com/ars

mechanism of ROS generation, which is the crucial initial step of cell death induced by HF-LPLI, and evaluated the antitumor effects of HF-LPLI. Our study reveals that HF-LPLI selectively photoinactivates its endogenous photoacceptor COX, induces a mitochondrial $\mathrm{O}_{2}^{-\bullet}$ burst via ETC, and, ulti- mately, produces oxidative damage on cancer cells. We demonstrate that the first reaction after laser absorption is the photo-oxidative damage of COX, which causes an in situ inhibition of the enzymatic activity of COX, leading to a significant mitochondrial $\mathrm{O}_{2}^{-\bullet}$ burst via ETC. This modality 

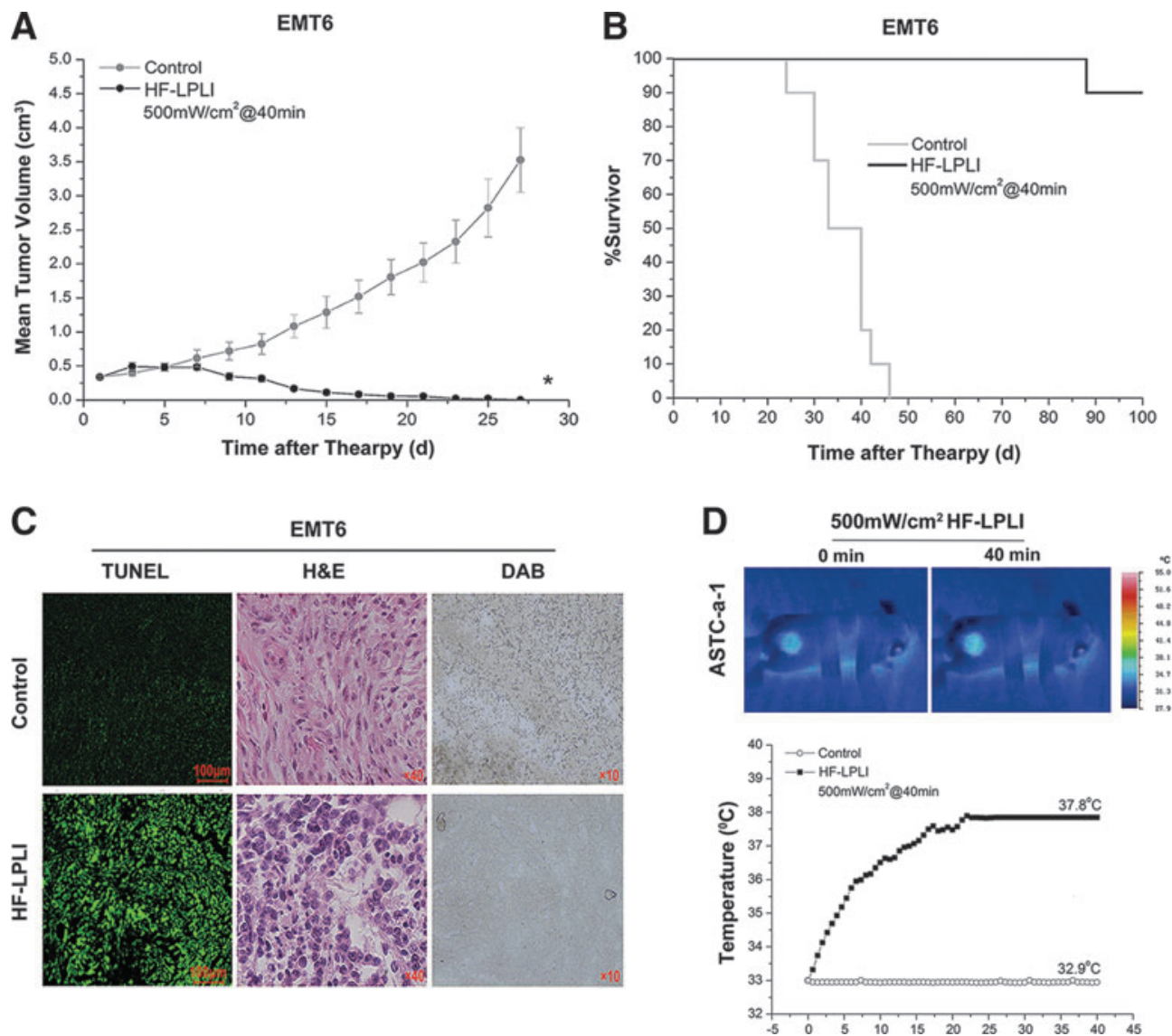

FIG. 7. In vivo tumor-killing efficacy of HF-LPLI $\left(500 \mathrm{~mW} / \mathrm{cm}^{2}\right.$ at $\left.40 \mathrm{~min}\right)$ in EMT6-transplanted tumor model. (A, B) Effects of HF-LPLI on EMT6-transplanted tumors in BALB/c mice. (A) Volumetric change in the tumor sizes of the tumorbearing mice that received HF-LPLI. The data represent the mean \pm SD $(n=10)$. ${ }^{*} P<0.05$ versus control. (B) Kaplan-Meier survival curves of the tumor-bearing mice that received HF-LPLI $(n=10)$. (C) Representative images of TUNEL-, H\&E-, and DAB-stained specimens from EMT6 tumors. (D) Average temperatures of ASTC-a-1 tumor surface during HF-LPLI treatment. Thermal imaging camera was used to evaluate the effect of temperature changes on the irradiated tumor surface during HF-LPLI treatment $(n=5)$. To see this illustration in color, the reader is referred to the web version of this article at www.liebertpub.com/ars

utilizes the two properties of COX, photoacceptor of HF-LPLI and complex IV of ETC, to kill cancer cells. Our study shows that HF-LPLI initiates its effects via targeted COX photoinactivation and that the tumor-killing efficacy depends on the subsequent mitochondrial $\mathrm{O}_{2}^{-} \bullet$ burst.

HF-LPLI-induced oxidative damage can be clearly demonstrated by the oxidation of GSH (Fig. 2F), a metabolic signal or an early warning of apoptosis (8). Oxidative stress by HFLPLI can also be evidenced by the damage to cellular macromolecules, including DNA, phospholipids, and proteins (Fig. 1E-G). The importance of a tight regulation of the mitochondrial redox balance is emphasized by the broad spectrum of mitochondrial antioxidant enzymes (27). Here, we discovered an elevated expression of MnSOD stimulated by HF-LPLI (Fig. 2G). Mainly located in mitochondrial matrix, MnSOD is well known as one of the major antioxidant enzymes against superoxide-free radicals (11). Overexpression of MnSOD has been reported to attenuate mitochondrial ROS generation, protect respiratory function, and even block apoptosis (11). Therefore, MnSOD up-regulation seems an important protective mechanism by which cancer cells counteract injuries caused by ROS.
It has been suggested that the mechanism of LPLI at the cellular level is based on the absorption of red-to-NIR light by COX (21). This photo-reactivity of COX is dependent on its four redox active metal centers: the binuclear $\mathrm{CuA}, \mathrm{CuB}$, heme a, and heme a3, all of which have absorbency in the red-to-NIR range (21). In ideal case, the action spectrum resembles the absorption spectrum of the molecule absorbing the light. Therefore, the bands in various action spectra in visible-to-NIR radiation in living cells were identified by analogy with the metal-ligand systems absorption spectra characteristic in this spectral range. This analysis allowed us to conclude that all bands in various action spectra with rather similar peak positions may be related to the $\operatorname{COX}(18,20,21)$. It is also evidenced that all bands present in the action spectra were present in the absorption spectra of the living cell monolayer as well (21). Dermatologists and photobiologists now consider COX as the photoacceptor in human skin when they received NIR radiation (31). However, the primary mechanism of light action after photon absorption has not yet been established, although several hypotheses exist. Currently, we found that COX activity was inhibited by HF-LPLI and that quenching ROS completely reversed this inhibition (Fig. 4). These observations 
suggest that irradiation may induce structural and functional changes to some of the COX components through an in situ photosensitized reaction. The photosensitized products are most likely ${ }^{1} \mathrm{O}_{2}$ or $\mathrm{O}_{2}{ }^{-\bullet}$, or possibly even both (Fig. $2 \mathrm{C}$ ). The mixed valence form of COX has been demonstrated to be required for its physiological function in the ETC $(14,34)$. Studies also suggest that the photoacceptor of red-to-NIR is one of the intermediate forms of COX redox cycle $(18,21)$. The photosensitized reaction triggered by HF-LPLI may contribute to the increased COX oxidation, making the enzyme fail to keep normal electron flow. On the other hand, it has been suggested that the changes in the degree of oxidation of the chromophores of COX caused by the irradiation are accompanied by conformational changes in their vicinity. Even small structural changes in the binuclear site of COX control both the rates of $\mathrm{O}_{2}$ reduction and the rates of the internal electron- and protontransfer reactions $(14,34)$.

Chen and Pervaiz reported that Bcl-2-mediated increase in COX activity was via the enhanced presence of COX Va and $\mathrm{Vb}$ in the mitochondria, indicative of a more complete and stable COX enzyme $(3,4)$. A similar result was shown in our current study that A549 cells overexpressing Bcl-2 transiently had nearly a twofold increase in COX activity (Supplementary Figs. S9 and S10). It is known that an elevated COX activity can accelerate the rate of electron flux through the entire ETC (34). The inhibition of COX activity in these conditions will cause a quick and more leak of electrons from complexes I and/or III to trigger an ROS burst. Therefore, cancer cells with elevated COX activity are highly susceptive to events that lead to oxidative stress and dysfunction of the mitochondrial machinery (13). Our current findings support this view, because once the activity of COX was inhibited by RNA interfere (RNAi), cell death rate declined (Fig. 5A, C and Supplementary Figs. S7 and S8). However, no obvious effect of Bcl-2 overexpression on HF-LPLI-induced cell apoptosis was observed (Supplementary Fig. S11). This phenomenon may be explained by the canonical role of $\mathrm{Bcl}-2$ in sequestrating pro-apoptotic proteins such as Bax and Bak, because Bax knockdown by RNAi had been reported to slightly delay HFLPLI-induced cell apoptosis (40).

Although COX is not a source of ROS, it is known that the inhibition of the oxidase can facilitate ROS production from complex I or III (6). The HF-LPLI-triggered mitochondrial $\mathrm{O}_{2}^{-\bullet}$ burst was due to COX photoinhibition, as evidenced by two clues in our current study. One is that the addition of SOD had no effect on COX inhibition by HF-LPLI, indicating that the mitochondrial $\mathrm{O}_{2}{ }^{-}$burst is a result of COX photoinhibition (Fig. 4C, D). Another is when the activity of COX was inhibited by COX III gene silencing, and the mitochondrial $\mathrm{O}_{2}{ }^{-\bullet}$ burst was fully prevented after HF-LPLI (Fig. 5B). A mitochondrial $\mathrm{O}_{2}{ }^{-\bullet}$ burst can induce cellular signaling cascades $(14,34)$. It has been reported that a mitochondrial ROS burst triggers the intrinsic pathway through the permeabilization of the outer mitochondrial membrane via the opening of MPT pores (22). All of the key apoptotic events in the intrinsic pathway were observed in HF-LPLI-treated cells, including the opening of transition pores, the release of cytochrome c, and the activation of caspase- 9 and caspase- 3 (5, $40,41,43)$. The mechanism how MPT pore is formed is rather complex and involves transcriptional and other regulatory mechanisms, including the alteration of the homeostasis of the Bcl-2 family proteins. Using isolated mitochondria, Narita et al. reported that proapoptotic Bcl-2 family proteins, Bax or Bak, can release cytochrome $\mathrm{c}$ by interacting with MPT pore components, in particular, the voltage-dependent anion channel (26). However, in our earlier study, Bax was not activated until outer mitochondrial membrane permeabilization by HF-LPLI (40), indicating that Bax is not participated in the induction of MPT. It is reported that truncated Bid (tBid) added to mouse liver mitochondria stimulated cytochrome $\mathrm{c}$ release via mechanisms which did not require the $\mathrm{BH} 3$-domain of $\mathrm{tBid}$ or the presence of Bak (Bax), but were sensitive to cyclosporine (CsA) (32). The ability of CsA to block tBid-induced release of cytochrome c suggested that the MPT pore complex was involved in this remodeling process. However, our previous results showed that Bid was not cleaved during the cell apoptosis process by HF-LPLI (41). This result indicates that Bid is not required for HFLPLI-induced MPT.

Our in vivo results demonstrated that, with a rational dosimetry, HF-LPLI could achieve high antitumor efficacy. Interestingly, HF-LPLI at $500 \mathrm{~mW} / \mathrm{cm}^{2}$ for $40 \mathrm{~min}$ resulted in the highest tumor-killing efficacy (Fig. 6A), suggesting that there is a critical window of irradiation fluence. With excessively high laser power intensity $\left(800 \mathrm{~mW} / \mathrm{cm}^{2}\right.$, Fig. 6A), rapid mitochondrial injury as a result of higher temperature and/or higher initial ROS production is likely to cause the cell to fail to generate physiological oxidative stress, resulting in a reduction in the subsequent cell death.

The reactivity of COX as the photoacceptor of red-to-NIR light depends on the absorption of light by its four redox active metal centers: the binuclear $\mathrm{CuA}, \mathrm{CuB}$, heme $\mathrm{a}$, and heme a3 (21). COX consists of 13 subunits in mammalian cells with the three catalytic subunits, COX I, II, and III, coded by the mitochondrial DNA. Heme a, heme a3, and $\mathrm{CuB}$ are ligated to COX I, while CuA is ligated to COX II $(30,45)$. It is reported that increased levels of RNA transcripts of COX I and II have been observed in liver, breast, and prostate neoplastic cells compared with normal tissue $(23,29)$. Therefore, it is reasonable to speculate that the increased levels of COX subunits will enhance the selectivity of HF-LPLI to treat these cancers. On the other hand, the catalytic efficiency of the COX can be enhanced by the nuclear-encoded COX subunits, such as COX IV, Vb, VIa, and VIb $(1,36)$. Recent studies have demonstrated an up-regulation and an increased involvement of COX Va, Vb, and COX IV in a variety of cancers, such as colorectal cancer, squamous cell cancer of the larynx, intraductal carcinoma of the breast, and prostate cancer $(2,15$, 38). More recently, it is directly demonstrated that epithelial cancer cells have higher levels of COX activity than normal adjacent epithelial cells, and even higher than stromal cells (37). It is known that an elevated COX activity can accelerate the rate of electron flux through the entire ETC. Hence, the inhibition of COX activity in these conditions will cause a quick and more leak of electrons, from complexes I and/or III of the ETC, to trigger ROS breakout. Therefore, cancer cells with elevated COX activity are highly vulnerable to events that lead to oxidative stress and dysfunction of the mitochondrial machinery. It is also reported that drug-resistant leukemic cell lines have more active mitochondrial function, which is associated with a greater susceptibility to tumor necrosis factor $\alpha$-induced respiratory inhibition (17). In our current study, low cell death rate was obtained once the activity of COX was inhibited by RNAi (Fig. 5A, C and 
Supplementary Figs. S7 and S8). This indicates that HF-LPLI has potentially significant applications against cancer with higher COX activity.

With the dose of $500 \mathrm{~mW} / \mathrm{cm}^{2}$ for $40 \mathrm{~min}$, we investigated the antitumor efficacy of HF-LPLI using two different solid tumor models. The tumor histopathology staining revealed a significant number of dead cells in the mouse tumors that received HF-LPLI (Figs. 6C and 7C). After HF-LPLI, the animal survival rate was improved compared with that of the control groups (Figs. 6B and 7B). Within several weeks, the treated area was healed (Fig. 6B inset). The in vivo generation of ROS in tumors during HF-LPLI therapy was also monitored using FCLA probe-based CL detection (Fig. 6E). These phenomena were completely absent in $\rho^{0}$ ASTC-a-1 xenografted tumor model, without tumor burden decrease (Fig. 6D) and ROS generation (Fig. 6E). DAB staining analysis demonstrated that HF-LPLI inhibited the enzymatic activity of COX in the tumor model (Figs. 6F and 7C), according to high-level cell death (Figs. 6F and 7C). These results suggest that the in vivo HF-LPLI modality of tumors is an oxidative damage effect via the ETC, with COX photoinactivation.

Previously, we reported that low-dose Photofrin-PDT could induce endogenous ROS production via ETC, which contributed to increased cell apoptosis (47). The results of this study suggest that mitochondria are not only targets but also a source of ROS during low-dose PDT, which may provide a novel approach to improve PDT applications. In our present study, HF-LPLI was able to directly inhibit the enzymatic activity of COX to trigger a mitochondrial $\mathrm{O}_{2}{ }^{-\bullet}$ burst without the involvement of any exogenous photosensitizer. Thus, the systematic toxicity, specifically the skin photosensitization, was completely eliminated. Finally, we demonstrated the mitochondria-targeting HF-LPLI as a novel modality of laser cancer therapy, which utilized COX as an endogenous photoacceptor. The enzymatic activity of COX was inhibited by the initial irradiation, and this gave rise to a burst of mitochondrial $\mathrm{O}_{2}^{-}$, resulting in effective tumor cell death. This modality is characterized by minimal phototoxicity to normal tissue and has the advantage of being a minimally invasive treatment with promising potential antitumor activities.

\section{Materials and Methods}

\section{Cell lines, tumor models, and reagents}

The A549 and EMT6 were obtained from American Type Culture Collection (ATCC, Manassas, VA). The ASTC-a-1 were obtained from Jinan University (Guangzhou, China) and used within 2 months after resuscitation. These cell lines were authenticated based on viability, recovery, growth, morphology, and isoenzymology by their suppliers. The ASTC-a-1 and A549 cells were grown in Dulbecco's modified Eagle's medium (Life Technologies, Inc., Grand Island, NY), and the EMT6 cells were grown in RPMI 1640 (GIBCO, Grand Island, NY) supplemented with 15\% fetal bovine serum (Gibco-BRL, Gaithersburg, MD), $50 \mathrm{U} / \mathrm{ml}$ penicillin, and $50 \mu \mathrm{g} / \mathrm{ml}$ streptomycin in $5 \% \mathrm{CO}_{2}$ at $37^{\circ} \mathrm{C}$ in a humidified incubator. In all experiments, $70-85 \%$ confluent cultures were used.

ASTC-a- 1 cells or $\rho^{0}$ ASTC-a- 1 cells $\left(1 \times 10^{6}\right)$ in a $100 \mu \mathrm{l}$ solution were injected into the flank region of female BALB/c nude mice aged $6-8$ weeks. EMT6 cells $\left(5 \times 10^{5}\right)$ in a $50 \mu 1$ solution were injected into the flank region of female BALB/c mice aged 6-8 weeks. The animals were used when the tumors reached a size of $\approx 300 \mathrm{~mm}^{3}$. The mice were randomly divided into different experimental groups and received various treatments.

$\mathrm{H}_{2}$ DCFDA, SE $(10 \mu M)$, DHE $(10 \mu M), \operatorname{MitoSOX}^{\mathrm{TM}}(5 \mu M)$, TMRM $(100 \mathrm{nM})$, and MTR $(100 \mathrm{nM})$ probes were purchased from Molecular Probes, Inc. (Eugene, OR). Rhodamine 123 $(5 \mu M)$ probe, DHA $(250 \mu M)$, NAC $(250 \mu M)$, and MnSOD $(50 \mathrm{U} / \mathrm{ml})$ were purchased from Sigma-Aldrich (St. Louis, MO). pDsRed-mit was presented by Prof. Yukiko Gotoh (University of Tokyo).

\section{Laser treatment}

For in vitro HF-LPLI, the cells were irradiated with a fiberoptic light delivery system $(635 \mathrm{~nm}, \mathrm{CW}$ semiconductor laser, NL-FBA-2.0-635; nLight Photonics Corporation, Vancouver, WA) for $10 \mathrm{~min}$ at a fluence rate of $50-200 \mathrm{~mW} / \mathrm{cm}^{2}$. For in vitro Photofrin-PDT, cells were incubated in the dark with Photofrin $(2.5 \mu \mathrm{g} / \mathrm{ml})$ in complete growth medium for $20 \mathrm{~h}$ and then rinsed with phosphate-buffered saline (PBS) before irradiation. The cells were irradiated with the 635-nm laser for $30 \mathrm{~s}$.

For in vivo HF-LPLI, the tumor-bearing mice were directly irradiated with the 635-nm laser. The total fluence delivered to the tumors was $1200 \mathrm{~J} / \mathrm{cm}^{2}$ with different fluence rate and irradiation time. During laser irradiation, the mice were anesthetized with an intraperitoneal injection (i.p.) of pentobarbital sodium ( $2 \%$ ) and were restrained in a specially designed holder. For in vivo Photofrin-PDT, Photofrin was administered i.p. at a dose of $10 \mathrm{mg} / \mathrm{kg} 24 \mathrm{~h}$ before irradiation. The light was delivered to the tumors using the 635-nm laser. The power density at the irradiated area was $112 \mathrm{~mW} / \mathrm{cm}^{2}$. The total laser fluence delivered to the tumors was $134 \mathrm{~J} / \mathrm{cm}^{2}$. After treatment, the mice were observed daily, and the tumors were measured every other day for a period of 100 days. The control samples were maintained on the laser table for the same amount of time used in the irradiated groups, but the laser source was not activated (sham irradiation).

\section{Live cell ROS detection using fluorescence probes}

$\mathrm{H}_{2}$ DCFDA, SE is a ROS-sensitive probe that can be used to detect ROS production in living cells. It passively diffuses into cells, where its acetate groups are cleaved by intracellular esterases, releasing the corresponding dichlorodihydrofluorescein derivatives $\mathrm{H}_{2}$ DCF. $\mathrm{H}_{2}$ DCF oxidation yields a fluorescent adduct, DCF that is trapped inside the cell. Cells were incubated at $37^{\circ} \mathrm{C}$ in the dark with $10 \mu \mathrm{M} \mathrm{H}_{2} \mathrm{DCFDA}, \mathrm{SE}$ in serum-free medium for $30 \mathrm{~min}$ and then, the DCF fluorescence was recorded using laser scanning microscope (LSM). Intracellular accumulation of $\mathrm{O}_{2}{ }^{-\bullet}$ was estimated using MitoSOX ${ }^{\mathrm{TM}}$, which selectively targets mitochondria and is oxidized by $\mathrm{O}_{2}^{-\bullet}$, emitting red fluorescence on binding to nucleic acids. Cells were loaded at $37^{\circ} \mathrm{C}$ with $5 \mu \mathrm{M}$ MitoSOX ${ }^{\mathrm{TM}}$ for $10 \mathrm{~min}$ in the dark, rinsed with PBS before fluorescence measurement by LSM. DHE is a cell-permeable blue fluorescent dye that on entering cells interacts with $\mathrm{O}_{2}{ }^{-\bullet}$ to form oxyethidium, which intercalates with nucleic acids and emits a red fluorescence which is detectable qualitatively by 
fluorescent microscopy. To assess $\mathrm{O}_{2}{ }^{-\bullet}$ production, cells were cultured in the dark with $10 \mu \mathrm{M}$ DHE diluted in PBS for $30 \mathrm{~min}$ at $37^{\circ} \mathrm{C}$ followed by a wash in PBS before being visualized by LSM.

\section{COX activity assay}

The enzymatic activity of COX in living cells was assayed by measuring cytochrome c oxidation using a COX Activity Testing Kit (Genmed Scientifics, Inc., Arlington, MA). The COX activity was determined by measuring the decrease in absorbance at $550 \mathrm{~nm}$ using an Infinite 2000 plate reader (TECAN, Mönnedorf, Switzerland). To analyze the enzymatic activity of COX in situ, DAB staining (Genmed, Boston, MA) was performed $1 \mathrm{~h}$ after each indicated treatment, and the middle sections of each tumor were formalin fixed and paraffin embedded following a standard routine.

\section{Cell death assays}

FACS was performed on an FACScanto II flow cytometer (BD Bioscience, San Jose, CA). For cellular apoptosis analysis, the annexin V-FITC/PI Apoptosis Detection Kit (BD PharMingen, San Diego, CA) was used as a standard reagent with excitation at $488 \mathrm{~nm}$. The fluorescent emission of FITC was measured at BP515-545 nm, and the emission of DNA-PI complexes was measured at BP564-606 nm. The number of events considered in FACS was 10,000 per each independent experiment. For in situ tumor cell death analysis, H\&E and TUNEL staining (Genmed, Boston, MA) was performed 1 day after the indicated treatments. The middle sections of each tumor were formalin fixed and paraffin embedded following a standard routine.

\section{Statistics}

For the fluorescence emission intensity analysis, a background subtraction was performed for all data. Each experiment was performed at least thrice. Statistical analysis was applied using the two-tailed Student's $t$-test. Representative data are shown for all other cases.

\section{Acknowledgments}

The authors acknowledge the financial support rendered by the National Basic Research Program of China (2011CB910402; 2010CB732602), the Program for Changjiang Scholars and Innovative Research Team in University (IRT0829), the National Natural Science Foundation of China (81101741, 61308111), the Research Fund for the Doctoral Program of Higher Education of China (20114407120002), and the Natural Science Foundation of Guangdong Province, China (S2011040003254).

\section{Author Disclosure Statement}

No competing financial interests exist.

\section{References}

1. Anthony G, Reimann A, and Kadenbach B. Tissue-specific regulation of bovine heart cytochrome-c oxidase activity by
ADP via interaction with subunit VIa. Proc Natl Acad Sci U S A 90: 1652-1656, 1993.

2. Bini L, Magi B, Marzocchi B, Arcuri F, Tripodi S, Cintorino M, Sanchez JC, Frutiger S, Hughes G, Pallini V, Hochstrasser DF, and Tosi P. Protein expression profiles in human breast ductal carcinoma and histologically normal tissue. Electrophoresis 18: 2832-2841, 1997.

3. Chen ZX and Pervaiz S. Bcl-2 induces pro-oxidant state by engaging mitochondrial respiration in tumor cells. Cell Death Differ 14: 1617-1627, 2007.

4. Chen ZX and Pervaiz S. Involvement of cytochrome c oxidase subunits $\mathrm{Va}$ and $\mathrm{Vb}$ in the regulation of cancer cell metabolism by Bcl-2. Cell Death Differ 17: 408-420, 2010.

5. Chu J, Wu S, and Xing D. Survivin mediates self-protection through ROS/cdc25c/CDK1 signaling pathway during tumor cell apoptosis induced by high fluence low-power laser irradiation. Cancer Lett 297: 207-219, 2010.

6. Dawson TL, Gores GJ, Nieminen AL, Herman B, and Lemasters JJ. Mitochondria as a source of reactive oxygen species during reductive stress in rat hepatocytes. Am J Physiol 264: C961-C967, 1993.

7. Eells JT, Wong-Riley MTT, VerHoeve J, Henry M, Buchman EV, Kane MP, Gould LJ, Das R, Jett M, Hodqolis B, Marqolis D, and Whelan HT. Mitochondrial signal transduction in accelerated wound and retinal healing by near-infrared light therapy. Mitochondrion 4: 559-567, 2004.

8. Franco R and Cidlowski JA. Apoptosis and glutathione: beyond an antioxidant. Cell Death Differ 16: 1303-1314, 2009.

9. Frigo L, Fávero GM, Lima HJ, Maria DA, Bjordal JM, Joensen J, Iversen VV, Marcos RL, Parizzoto NA, and LopesMartins RA. Low-level laser irradiation (InGaAlP-660 nm) increases fibroblast cell proliferation and reduces cell death in a dose-dependent manner. Photomed Laser Surg 28: S151S156, 2010.

10. Gao X and Xing D. Molecular mechanisms of cell proliferation induced by low power laser irradiation. J Biomed Sci 16: 4, 2009 .

11. Giovambattista P, Renata C, Barbara B, Salvatore F, Daniela F, Silvia B, and Tommaso G. Mitochondrial superoxide dismutase: a promising target for new anticancer therapies. Curr Med Chem 11: 1299-1308, 2004.

12. Gogvadze V, Orrenius S, and Zhivotovsky B. Mitochondria in cancer cells: what is so special about them? Trends Cell Biol 18: 165-173, 2008.

13. Halliwell B. Oxidative stress and cancer: have we moved forward? Biochem J 401: 1-11, 2007.

14. Hamanaka RB and Chandel NS. Mitochondrial reactive oxygen species regulate cellular signaling and dictate biological outcomes. Trends Biochem Sci 35: 505-513, 2010.

15. Herrmann PC, Gillespie JW, Charboneau L, Bichsel VE, Paweletz CP, Calvert VS, Kohn EC, Emmert-Buck MR, Liotta LA, and Petricoin EF 3rd. Mitochondrial proteome: altered cytochrome c oxidase subunit levels in prostate cancer. Proteomics 3: 1801-1810, 2003.

16. Huang $\mathrm{L}, \mathrm{Wu} \mathrm{S}$, and Xing D. High fluence low-power laser irradiation induces apoptosis via inactivation of Akt/GSK3 $\beta$ signaling pathway. J Cell Physiol 226: 588-601, 2011.

17. Jia L, Kelsey SM, Grahn MF, Jiang XR, and Newland AC. Increased activity and sensitivity of mitochondrial respiratory enzymes to tumor necrosis factor alpha-mediated inhibition is associated with increased cytotoxicity in drug-resistant leukemic cell lines. Blood 87: 2401-2410, 1996. 
18. Karu TI. Primary and secondary mechanisms of action of visible-to-near IR radiation on cells. J Photochem Photobiol B Biol 49: 1-17, 1999.

19. Karu TI. Multiple roles of cytochrome c oxidase in mammalian cells under action of red and IR-A radiation. IUBMB Life 62: 607-610, 2010.

20. Karu TI and Kolyakov SF. Exact action spectra for cellular responses relevant to phototherapy. Photomed Laser Surg 23: 355-361, 2005.

21. Karu TI, Pyatibrat L, Kolyakov S, and Afanasyeva N. Absorption measurements of a cell monolayer relevant to phototherapy: reduction of cytochrome c oxidase under near IR radiation. J Photochem Photobiol B Biol 81: 98-106, 2005.

22. Kroemer G, Galluzzi L, and Brenner C. Mitochondrial membrane permeabilization in cell death. Physiol Rev 87: 99 $163,2007$.

23. Luciakova $\mathrm{K}$ and Kuzela S. Increased steady-state levels of several mitochondrial and nuclear gene transcripts in rat hepatoma with a low content of mitochondria. Eur J Biochem 205: 1187-1193, 1992.

24. Marcus RA and Sutin N. Electron transfer in chemistry and biology. Biochem Biophys Acta 811: 265-322, 1985.

25. Murayama H, Sadakane K, Yamanoha B, and Kogure S. Low-power 808-nm laser irradiation inhibits cell proliferation of a human-derived glioblastoma cell line in vitro. Lasers Med Sci 27: 87-93, 2012.

26. Narita M, Shimizu S, Ito T, Chittenden T, Lutz RJ, Matsuda $\mathrm{H}$, and Tsujimoto $\mathrm{Y}$. Bax interacts with the permeability transition pore to induce permeability transition and cytochrome c release in isolated mitochondria. Proc Natl Acad Sci U S A 95: 14681-14686, 1998.

27. Orrenius S, Gogvadze V, and Zhivotovsky B. Mitochondrial oxidative stress: implications for cell death. Annu Rev Pharmacol Toxicol 47: 143-183, 2007.

28. Pastore D, Greco M, and Passarella S. Specific helium-neon laser sensitivity of the purified cytochrome c oxidase. Int J Rad Biol 76: 863-870, 2000.

29. Penta JS, Johnson FM, Wachsmanb JT, and Copeland WC. Mitochondrial DNA in human malignancy. Mutat Res 488: 119-133, 2001.

30. Regan JJ, Ramirez BE, Winkler JR, Gray HB, and Malmstrom BG. Pathways for electron tunneling in cytochrome c oxidase. J Bioenerg Biomembr 30: 35-39, 1998.

31. Schroeder P, Pohl C, Marks C, Calles C, Wild S, and Krutmann J. Cellular response to infrared radiation involves retrograde mitochondrial signaling. Free Radic Biol Med 43: 128-135, 2007.

32. Scorrano L, Ashiya M, Buttle K, Weiler S, Oakes SA, Mannella CA, and Korsmeyer SJ. A distinct pathway remodels mitochondrial cristae and mobilizes cytochrome c during apoptosis. Dev Cell 2: 55-67, 2002.

33. Tata DB and Waynant RW. Laser therapy: a review of its mechanism of action and potential medical applications. Laser Photonics Rev 5: 1-12, 2011.

34. Turrens JF. Mitochondrial formation of reactive oxygen species. J Physiol 552: 335-344, 2003.

35. Wang F, Chen $\mathrm{T}$, Xing D, Wang J, and Wu Y. Measuring dynamics of caspase- 3 activity in living cells using FRET technique during apoptosis induced by high fluence lowpower laser irradiation. Lasers Surg Med 36: 2-7, 2005.

36. Weishaupt A and Kadenbach B. Selective removal of subunit $\mathrm{VIb}$ increases the activity of cytochrome c oxidase. Biochemistry 31: 11477-11481, 1992.
37. Whitaker-Menezes D, Martinez-Outschoorn UE, Flomenberg N, Birbe RC, Witkiewicz AK, Howell A, Pavlides S, Tsirigos A, Ertel A, Pestell RG, Broda P, Minetti C, Lisanti $\mathrm{MP}$, and Sotgia F. Hyperactivation of oxidative mitochondrial metabolism in epithelial cancer cells in situ. Cell Cycle 10: 4047-4064, 2011.

38. Wu H, Rao GN, Dai B, and Singh P. Autocrine gastrins in colon cancer cells up-regulate cytochrome $\mathrm{c}$ oxidase $\mathrm{Vb}$ and down-regulate efflux of cytochrome $c$ and activation of caspase-3. J Biol Chem 275: 32491-32498, 2000.

39. Wu S and Xing D. Intracellular signaling cascades following light irradiation. Laser Photonics Rev [Epub ahead of print]; DOI: 10.1002/lpor.201300015.

40. Wu S, Xing D, Gao X, and Chen WR. High fluence lowpower laser irradiation induces mitochondrial permeability transition mediated by reactive oxygen species. J Cell Physiol 218: 603-611, 2008.

41. Wu S, Xing D, Wang F, and Chen WR. Mechanistic study of apoptosis induced by high fluence low-power laser irradiation using fluorescence imaging techniques. J Biomed Opt 2: 064015, 2007.

42. Wu S, Zhou F, Zhang Z, and Xing D. Bax is essential for Drp1-mediated mitochondrial fission but not for mitochondrial outer membrane permeabilization caused by photodynamic therapy. J Cell Physiol 226: 530-541, 2011.

43. Wu S, Zhou F, Zhang Z, and Xing D. Mitochondrial oxidative stress causes mitochondrial fragmentation via differential modulation of mitochondrial fission/fusion protein. FEBS J 278: 941-954, 2011.

44. Xing D and Wu S. Chapter 47. LLLT signaling pathways. In: Handbook of Photomedicine, edited by Hamblin MR and Huang Y. London, United Kingdom: Taylor \& Francis, 2013, pp. 535-556.

45. Yoshikawa S. X-ray structure and reaction mechanism of bovine heart cytochrome c oxidase. Biochem Soc T 27: 351362, 1999.

46. Zhang J, Xing D, and Gao X. Low-power laser irradiation activates Src tyrosine kinase through reactive oxygen species-mediated signaling pathway. J Cell Physiol 217: 518$528,2008$.

47. Zhao H, Xing D, and Chen Q. New insights of mitochondria reactive oxygen species generation and cell apoptosis induced by low dose photodynamic therapy. Eur J Cancer 47: 2750-2761, 2011.

48. Zhou F, Xing D, and Chen WR. Regulation of HSP70 on activating macrophages using PDT-induced apoptotic cells. Cancer Lett 264: 135-144, 2008.

$$
\begin{array}{r}
\text { Address correspondence to: } \\
\text { Prof. Da Xing } \\
\text { MOE Key Laboratory of Laser Life } \\
\text { Science and Institute of Laser Life Science } \\
\text { College of Biophotonics } \\
\text { South China Normal University } \\
\text { Guangzhou 510631 } \\
\text { China } \\
\text { E-mail: xingda@scnu.edu.cn }
\end{array}
$$

Date of first submission to ARS Central, February 5, 2013; date of final revised submission, August 9, 2013; date of acceptance, September 1, 2013. 


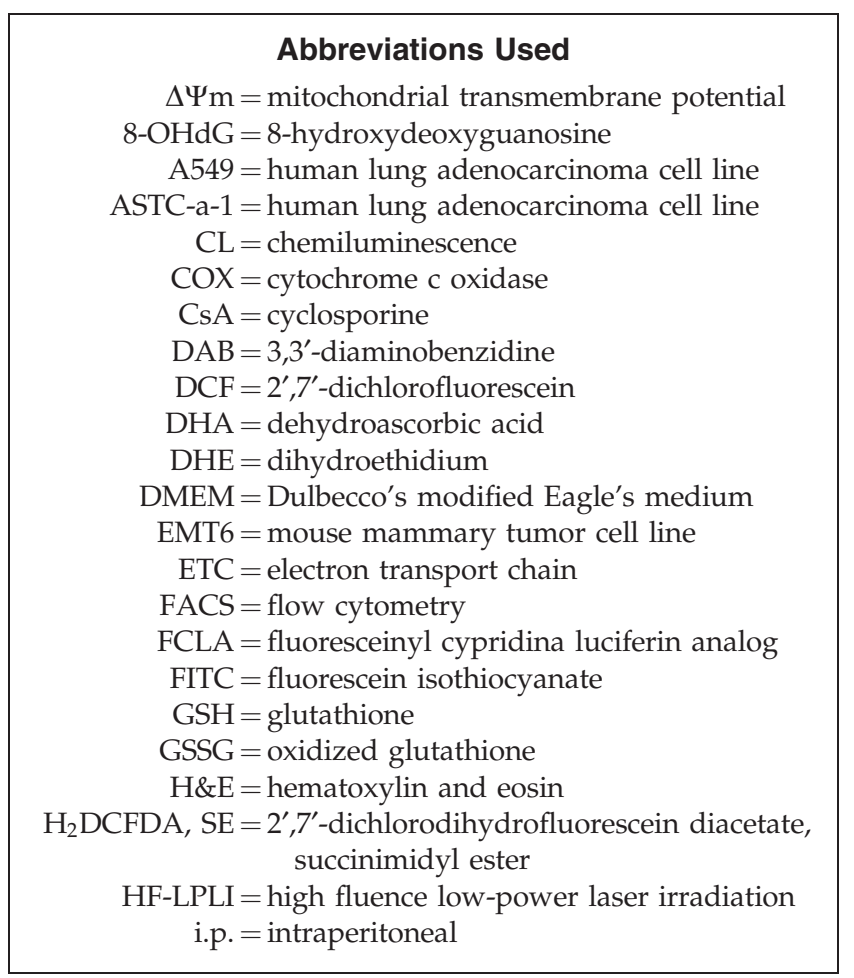

$\begin{aligned} \mathrm{LPLI} & =\text { low-level laser irradiation } \\ \mathrm{LSM} & =\text { laser scanning miscroscope } \\ \mathrm{MDA} & =\text { malondialdehyde } \\ \mathrm{MnSOD} & =\text { manganese superoxide dismutase } \\ \mathrm{MPT} & =\text { mitochondrial permeability transition } \\ \mathrm{MTR} & =\text { MitoTraker Deeper Red } 633 \\ \mathrm{NAC} & =\text { - } \text {-acetyl-L-cysteine } \\ \mathrm{NIR} & =\text { near infrared } \\ { }^{1} \mathrm{O}_{2} & =\text { singlet oxygen } \\ \mathrm{O}_{2} & =\text { molecular oxygen } \\ \mathrm{O}_{2}{ }^{-} & =\text {superoxide anion } \\ \mathrm{PBS} & =\text { phosphate-buffered saline } \\ \mathrm{PDT} & =\text { photodynamic therapy } \\ \mathrm{PI} & =\text { propidium iodide } \\ \mathrm{pNA} & =\text { p-nitroaniline } \\ \mathrm{Rh} 123 & =\text { rhodamine } 123 \\ \mathrm{RNAi} & =\text { RNA interfere } \\ \mathrm{ROS} & =\text { reactive oxygen species } \\ \mathrm{SD} & =\text { standard deviation } \\ \mathrm{siRNA} & =\text { small interfering RNA } \\ \mathrm{SOD} & =\text { superoxidase dismutase } \\ \mathrm{tBid} & =\text { truncated Bid } \\ \mathrm{TMRM} & =\text { tetramethylrhodamine methyl ester } \\ \mathrm{TUNEL} & =\text { terminal deoxynucleotidyl transferase } \\ & \text { dUTP nick end labeling } \\ & \end{aligned}$

